\title{
CURVED STRUCTURE ANALYSIS FOR TYPICAL LOADING WITH RESTRAINED BOUNDARY CONDITION, USING ISOPARAMETRIC BEAM ELEMENT
}

\section{DR. VIKAS GANDHE}

Professor, School of Architecture, I.P.S. Academy, Indore, Madhya Pradesh, India

ABSTRACT

Analysis of curved structures for different loading patterns and boundary conditions creates complications due to inter-action of in-plane and bending stresses. Due to the availability of fast-running computers, all the complicated structures were now easily analyzed using the Finite Element Method. This paper deals with such types of complicated structures as the Helical staircase, which was not only curved in the plan but also curved in elevation too. Analysis of helical staircase with $90^{\circ}$ helix angle, 3.6m floor height, and 200mm waist-slab thickness, was carried out for both the restrained support conditions, along with four types of loading pattern. Types of loading were: UDL over entire length; UDL over bottom half-length; UDL over top half-length; Point load at quarter lengths. Using the Finite Element Method Semi-loof beam element was used to analyze the selected staircase. The total staircase was discretized in six equal elements, through 13 nodal points with in-all 72 d.o.f. Results thus obtained for inplane \& bending stresses as well as displacements; were plotted and shown in a tubular form also. KEYWORDS: Boundary Condition - Displacement - Force Resultant, Helix - Isoparametric \& Semilo of Beam

Received: Apr 09, 2021; Accepted: Apr 29, 2021; Published: May 17, 2021; Paper Id.: IJCSEIERDJUN202112

\section{INTRODUCTION}

For any structures, specifically for the curved structures, exact analysis under different loading patterns and support boundary conditions was an essential requirement. For simple and determinate structure, analysis and stress distribution can be very easily and quickly calculated with well-known methods. But in the case of curved structures, exact analysis can only be carried out by special methods, based on fast running computers. It was a well-established fact, that the analysis of curved structures with different boundary conditions and loading patterns creates complications due to the interaction of in-plane and bending stresses. Suitable numerical methods have remarkably gained popularity for analyzing the curved structures with great accuracy, as well as saving huge manhours, with minimum time consumption. The finite Element Method is selected using an isoperimetric beam element. 


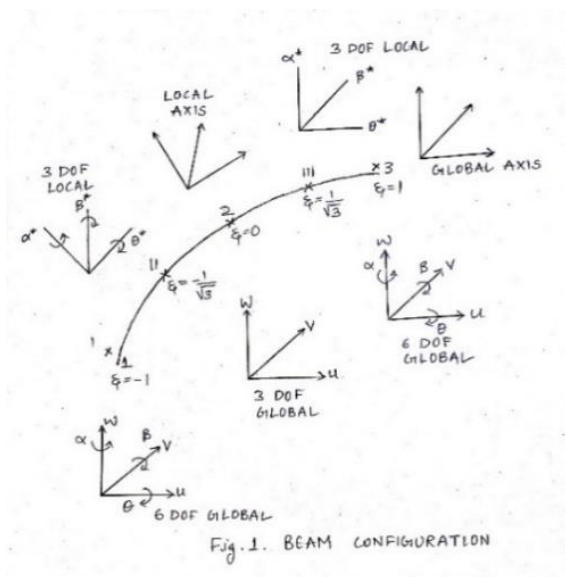

Figure 1: The Basic Nodal Configuration for the Beam Elements was Shown in.

This element hada total of 21 d.o.f. This total of 21 d.o.f. was used to predict axial forces, transverse shears, bending, torsional, values as well as displacements. To analyze the curved structure, a helical staircase of $90^{\circ}$ helix angles was considered. This curved structure was not the only curve in the plan but it is curved in elevation also. The total helix height i.e., height between the floors was taken as $3.6 \mathrm{~m}$. The waist slab thickness was kept $200 \mathrm{~mm}$ constant throughout. An inner radius was $500 \mathrm{~mm}$, while the outer radius was considered as $1500 \mathrm{~mm}$. The whole staircase was discretized in six equal curved elements. The total number of nodal points was taken as 13 with a total of 72 degrees of freedom.

As support conditions, both top and bottom supports were firmly restrained. The curved structure was analyzed by imposing four types of loading:

- $\quad$ U.D.L. of $5 \mathrm{kN} / \mathrm{m}$ over an entire length;

- U.D.L. of $5 \mathrm{KN} / \mathrm{m}$ over bottom three elements i.e., element no. 1,2 , and 3 .

- U.D.L. of $5 \mathrm{KN} / \mathrm{m}$ over the top half of three elements as element no. 4,5 , and 6.

- Similarly, a point load of $1 \mathrm{KN}$ was applied at the quarter length of helical stairs from the top as well as from the bottom i.e., at nodes no. 4 and 10.

The displacement, force resultants, and moments resultants in all three directions were calculated and shown graphically. The salient points for maximum values were also shown in a tabular form.

\section{METHODOLOGY}

The exact stress pattern for the curved structures was complicated. Analysis of these structures was more complicated when applied with various boundary conditions and loading patterns. The analysis of these curved structures as helicord staircase was carried out by using the latest scientific/computer method as Finite Element Method using loof beam element. The whole analysis was carried out to predict displacements, and transverse shears, bending, and torsional moments in all three global directions.

The following parameters were selected

- Helical staircase with total helix angle $=90^{\circ}$ 
- $\quad$ Total height of staircase $=3.6 \mathrm{~m}$

- The waist slab thickness $=200 \mathrm{~mm}$

- $\quad$ Inner radius $=500 \mathrm{~mm}$

- $\quad$ Outer radius $=1500 \mathrm{~mm}$

- Area of cross section $=2 \times 10^{5} \mathrm{~mm}^{2}$

- Modulus of elasticity, $\mathrm{E}=0.12 \times 10^{5} \mathrm{~N} / \mathrm{mm}^{2}$

- Modulus of rigidity, $\mathrm{G}=0.52173 \times 10^{4} \mathrm{~N} / \mathrm{mm}^{2}$

- Moment of Inertia, $\mathrm{I}_{\mathrm{zz}}=66.66 \times 10^{5} \mathrm{~mm}^{4}$

- Moment of Inertia, $\mathrm{I}_{\mathrm{yy}}=16.66 \times 10^{9} \mathrm{~mm}^{4}$

- Polar moment of Inertia, $\mathrm{I}_{\mathrm{p}}=2.288 \times 10^{8} \mathrm{~mm}^{4}$

- Unit weight of R.C.C. $=24 \mathrm{KN} / \mathrm{m}^{3}$

- Poisson's Ratio, $\mu=0.15$

The whole structure was discretized in six equal elements.

Total no. of d.o.f. $=72$

Total no. of nodal points $=13$

Boundary conditions: both top and bottom supports were restrained completely.

Load cases: a total of four types of loads were taken into considerations for the analysis of the helical staircase.

Case 1: a uniformly distributed load of $5 \mathrm{KN} / \mathrm{m}$ over the entire span length i.e., over a total of six elements.

Case 2: a uniformly distributed load of $5 \mathrm{KN} / \mathrm{m}$ over the bottom half-length of total span i.e., over element no. 1, 2 and 3.

Case 3: uniformly distributed load of $5 \mathrm{KN} / \mathrm{m}$ over the top half-length of total span i.e., over an element no. 4,5 , and 6.

Case 4: point load of $1 \mathrm{KN}$ at each quarter length from the bottom \& top supports. i.e., node no. 4 and no. 10

\section{OBSERVATION}

The whole curved helical with $90^{\circ}$ helix angles was analyzed, using a computer program with different required subroutines. The parameters thus obtained for all the four loading cases, mentioned above, as well as for top \& bottom supports in restrained conditions, were shown graphically as well as in a tabular form to assess the conclusion. 


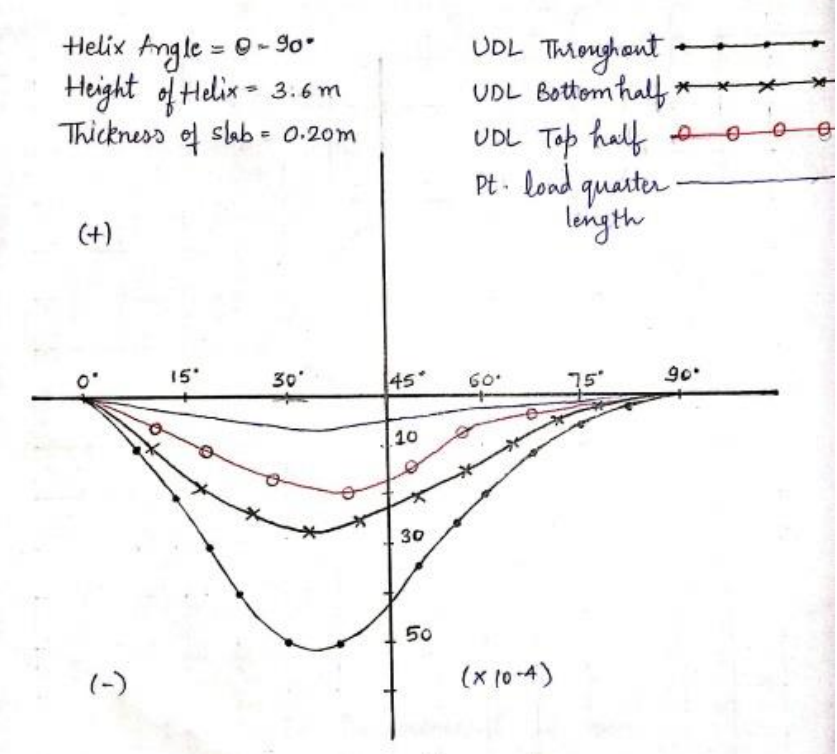

Fig. 2. ' $U$ ' Displacement in $m \cdot m$

Figure 2: The Displacement in ' $U$ ' Direction in $\mathbf{m m}$, over the Entire Length of the Structure, with four Loadings, was Shown in.

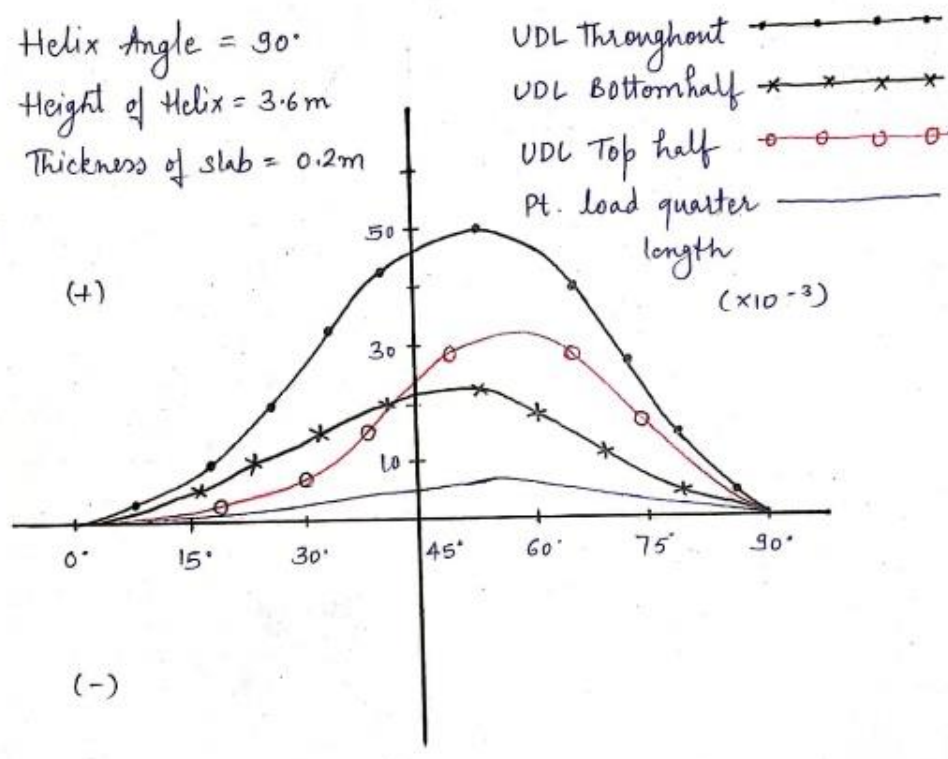

Fig.3 ' $V$ ' Displacement in $\mathrm{mm}$

Figure 3: Similarly for all the Four Types of Loads Applied to Predict the ' $V$ ' Displacement in mm Graphically shown in. 


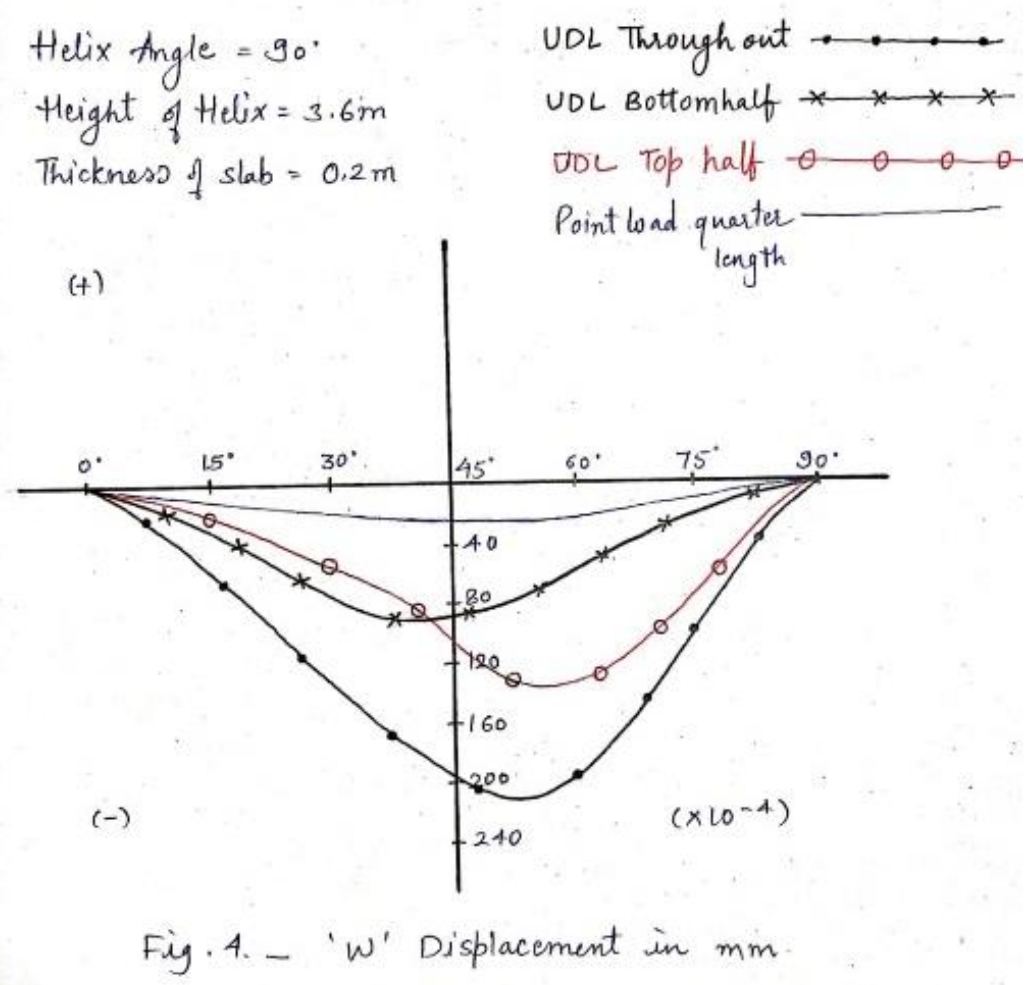

- $\quad$ The displacement in ' $\mathrm{W}$ ' direction in $\mathrm{mm}$, to analyze the curved helicoid staircase for all the four types of loading were predicted and shown graphically in Figure 4

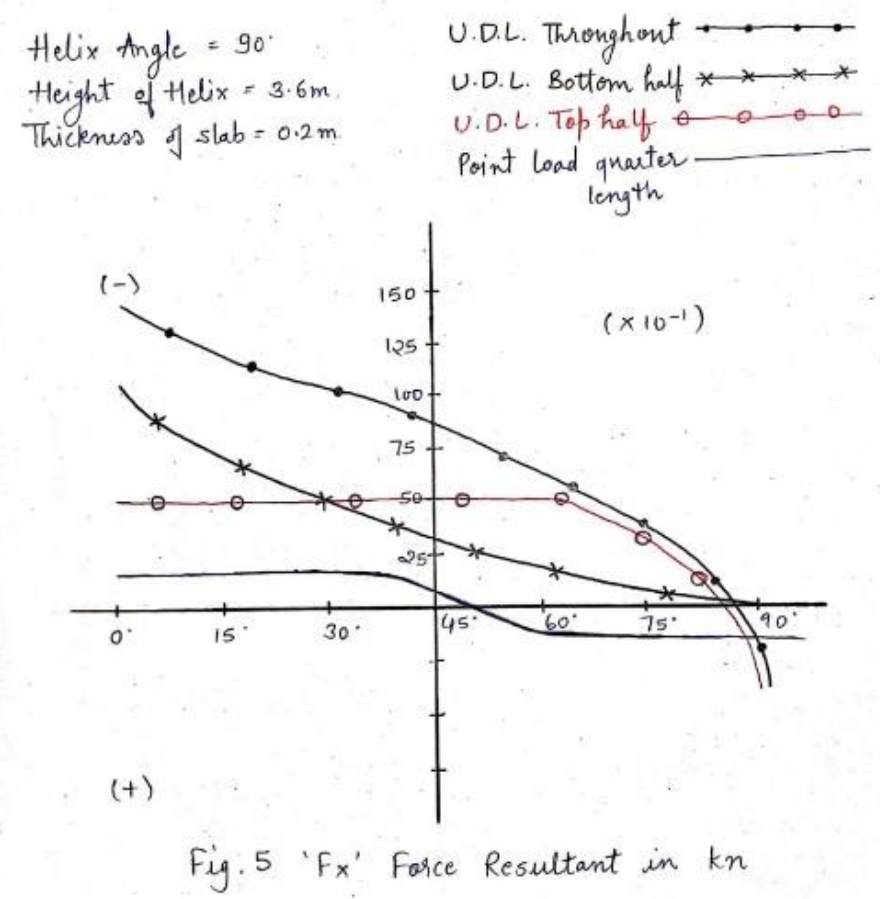

- The force resultant " $\mathrm{F}_{\mathrm{x}}$ " in $\mathrm{KN}$ was predicted for all the four types of loading, mention above, were graphically 
displayed in Figure. 5

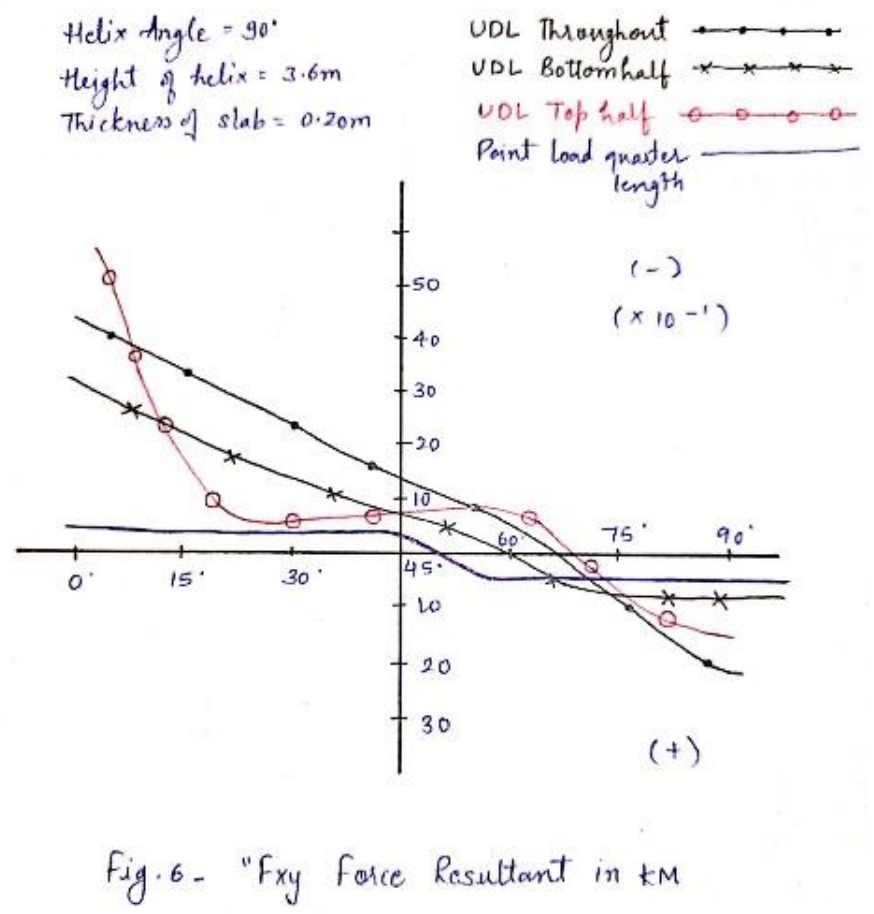

- The force resultant " $\mathrm{F}_{\mathrm{xy}}$ " in $\mathrm{KN}$ were obtained for U.D.L. over the top half-length of the staircase and point load, applied at quarter length from the top as well as from bottom; and displayed graphically in Fig. 6

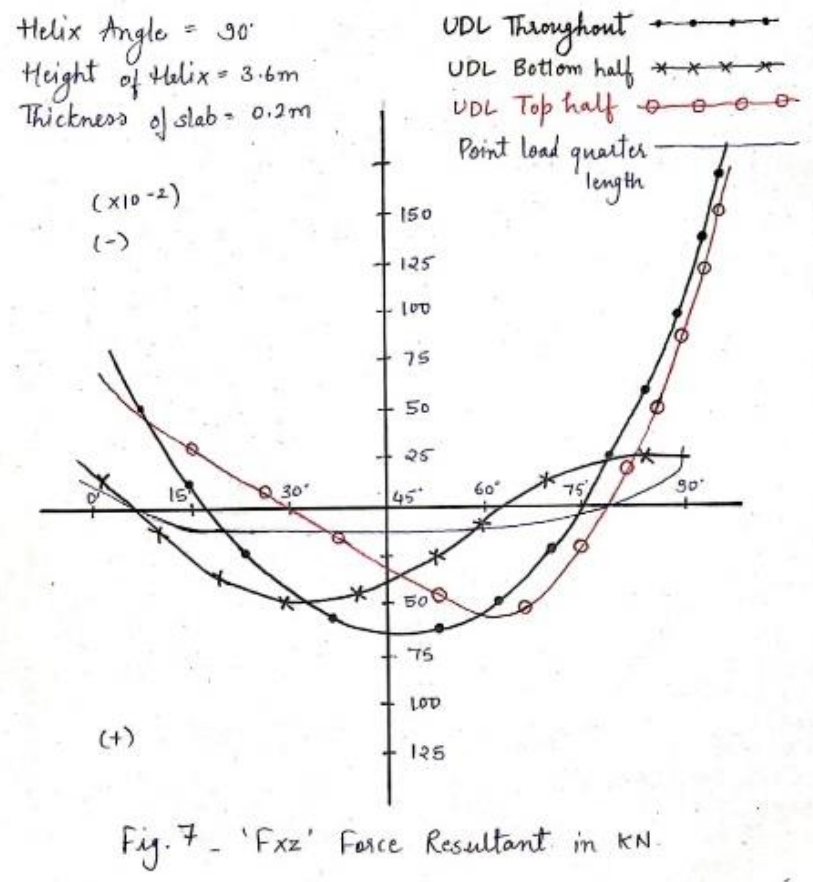

- Similarly, the force resultant " $\mathrm{F}_{\mathrm{xz}}$ " in $\mathrm{KN}$ was obtained for full-length U.D.L. over element no. 1 to element no. 6. 
In addition to the above loading, other remaining three loadings were applied and the result thus obtained were plotted and displayed in Figure. 7

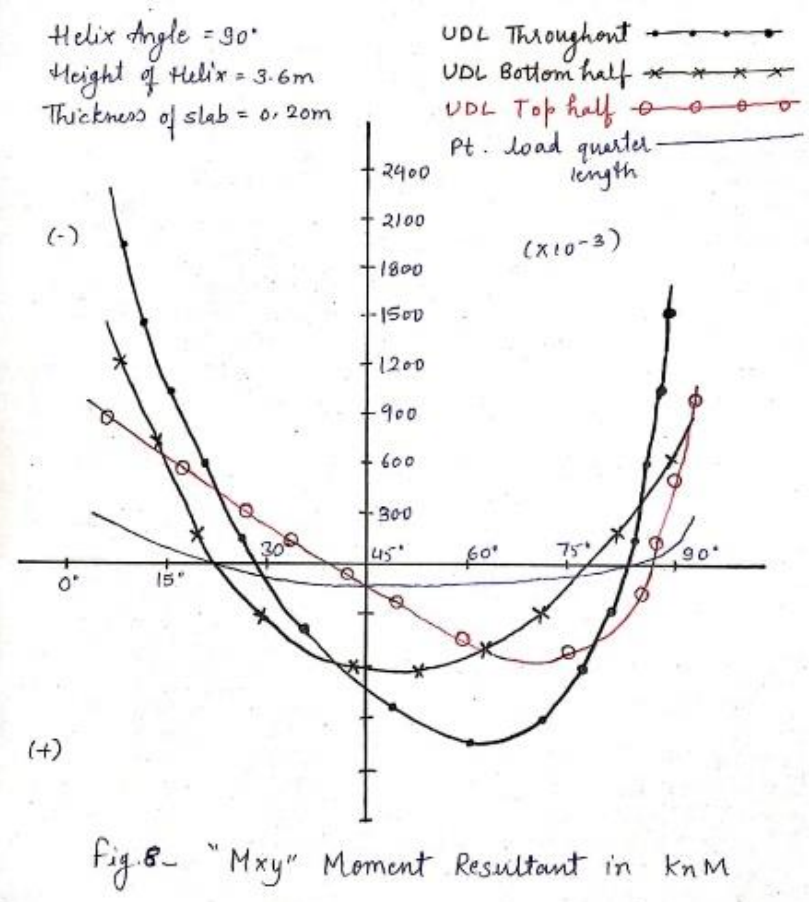

- Moment Resultants: The moment resultant " $\mathrm{M}_{\mathrm{xy}}$ " in $\mathrm{KN}-\mathrm{M}$ for the typical four loadings applied tothe helical staircase was plotted and shown graphically in Figure. 8

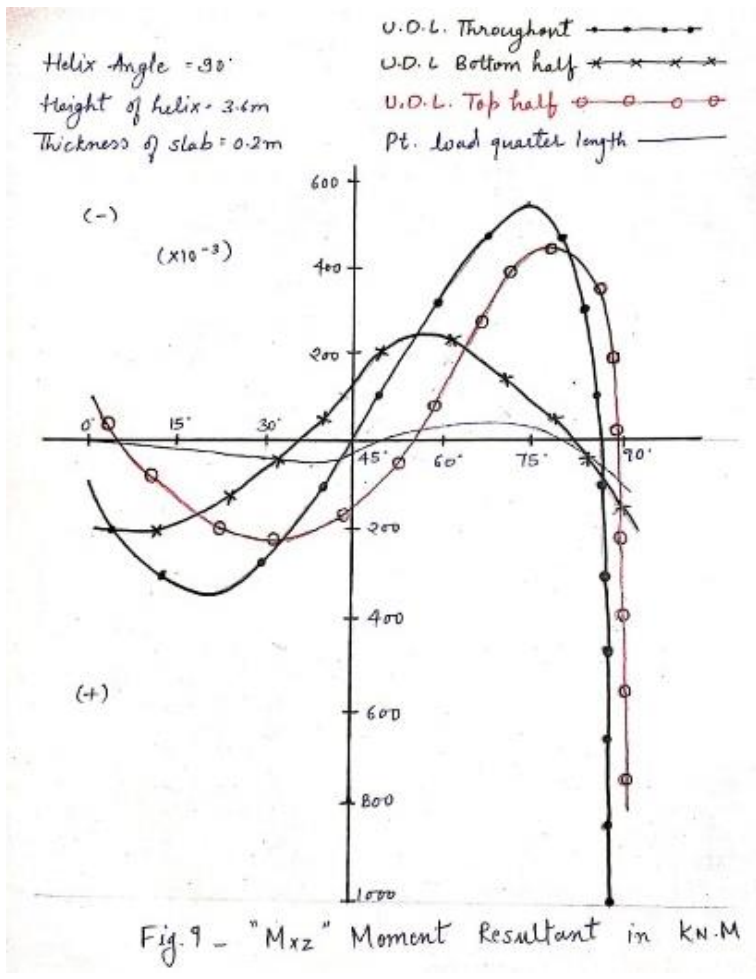


- The moment resultant " $\mathrm{M}_{\mathrm{xz}}$ " in $\mathrm{KN}-\mathrm{M}$ were obtained after analyzing the curved helical structure for restrained boundary conditions \& other four types of loading, already mentioned above, were shown graphically in Figure. 9

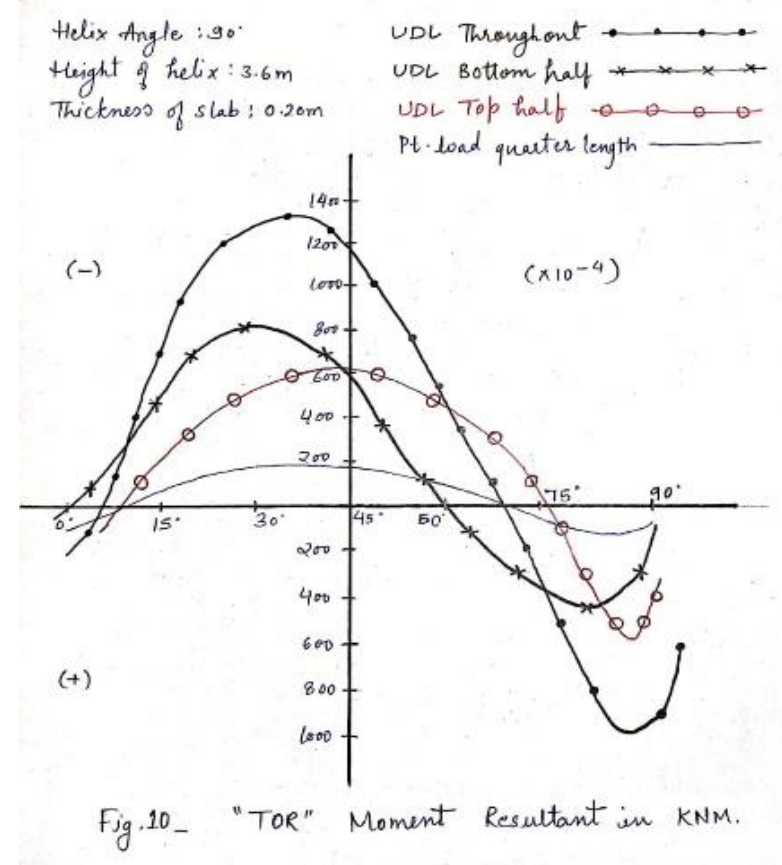

- The torsional moment resultant "TOR" in KN-M was plotted for restrained boundary conditions and well-selected four types of loading, in Figure. 10

- The salient value for nodal displacements for $\mathrm{U}, \mathrm{V} \& \mathrm{~W}$ directions were shown in table 1

Table 1: Showing Displacement in MM

\begin{tabular}{|c|l|c|c|c|}
\hline S.No. & \multicolumn{1}{|c|}{ TYPES OF LOAD } & 'U' & 'V' & 'V' \\
\hline 1 & UDL Throughout & $50 \times 10^{-4}$ & $50 \times 10^{-3}$ & $50 \times 10^{-4}$ \\
\hline 2 & UDL Bottom half & $30 \times 10^{-4}$ & $21 \times 10^{-3}$ & $86 \times 10^{-4}$ \\
\hline 3 & UDL Top half & $21 \times 10^{-4}$ & $31 \times 10^{-3}$ & $140 \times 10^{-4}$ \\
\hline 4 & Point load quarter length & $5 \times 10^{-4}$ & $5 \times 10^{-3}$ & $23 \times 10^{-4}$ \\
\hline
\end{tabular}

- The salient values of stress resultants $F_{x}, F_{x y} \& F_{x z}$ were displayed in Table 2

Table 2: Showing Force Resultant in KN

\begin{tabular}{|c|l|c|c|c|}
\hline S. No. & \multicolumn{1}{|c|}{ Types of Load } & ${ }^{\prime} \mathbf{F}_{\mathbf{x}}{ }^{\prime}$ & ${ }^{\prime} \mathbf{F}_{\mathbf{x y}}$ & ${ }^{\prime} \mathbf{F}_{\mathbf{x z}}$ \\
\hline 1 & UDL Throughout & $135 \times 10^{-1}$ & $40 \times 10^{-1}$ & $240 \times 10^{-2}$ \\
\hline 2 & UDL Bottom half & $85.5 \times 10^{-4}$ & $30 \times 10^{-1}$ & $23 \times 10^{-2}$ \\
\hline 3 & UDL Top half & $50 \times 10^{-4}$ & $96 \times 10^{-1}$ & $220 \times 10^{-2}$ \\
\hline 4 & Point load quarter length & $14 \times 10^{-4}$ & $4 \times 10^{-1}$ & $27 \times 10^{-2}$ \\
\hline
\end{tabular}

- The salient values for moment resultants as " $\mathrm{M}_{\mathrm{xy}}, \mathrm{M}_{\mathrm{xz}}$, TOR, were displayed in a tabular form in Table 3

Table 3: Showing Moment Resultant in KN-M

\begin{tabular}{|c|l|l|l|l|}
\hline S.No. & Types of Load & ${ }^{\prime} \mathbf{M}_{\mathbf{x y}}{ }^{\prime}$ & ${ }^{\prime} \mathbf{M}_{\mathbf{x z}}{ }^{\prime}$ & 'TOR' \\
\hline 1 & UDL Throughout & $2400 \times 10^{-1}$ & $990 \times 10^{-3}$ & $1300 \times 10^{-4}$ \\
\hline 2 & UDL Bottom half & $1500 \times 10^{-4}$ & $220 \times 10^{-3}$ & $800 \times 10^{-4}$ \\
\hline 3 & UDL Top half & $950 \times 10^{-4}$ & $780 \times 10^{-3}$ & $660 \times 10^{-4}$ \\
\hline 4 & Point load quarter length & $280 \times 10^{-4}$ & $130 \times 10^{-3}$ & $150 \times 10^{-4}$ \\
\hline
\end{tabular}




\section{CONCLUSIONS}

- The maximum displacement in the " $U$ " direction is $15^{0}$ from the center of the span, towards the bottom support.

- Displacement "V" direction for all the four selected load cases, it was observed that the maximum displacement in $15^{0}$ from the center of the span, towards the top support.

- Maximum "W" displacement for the selected loading condition is maximum, $15^{0}$ from the center of the staircase towards the top support.

- The maximum value of force resultant " $F_{x}$ " \& " $F_{y}$ " is maximum at bottom support only.

- The value of force resultant " $F_{x z}$ " was observed to be maximum at the top support of the helix staircase.

- Effect of selected loadings for moment resultant " $\mathrm{M}_{\mathrm{xy}}$ " was observed to be maximum

- The effect of "TOR" (Torsional Moment Resultant) is the bare minimum and behaves like a sinusoidal wave.

\section{REFERENCES}

1. Ahmed. S., "Curved Finite Element in the analysis of solid shells and plate structure" Ph.D. thesis, University of Wales; Swansea; (1969)

2. Borgar, F.R. and Fox, R.L. and Schmit, L.A.; "A cylindrical shell discrete element." A.I.A.A. Journal; Vol 5, 1967, pp. 745

3. Gandhe, Vikas. "Stress Resultants of Curved Structure for Typical Loadings by Isoparametric Beam Element. "International Journal of Civil, Structural, Environmental and Infrastructure Engineering Research and Development (IJCSEIERD) 8.5, Dec 2018, 37-44

4. Iron; B.M. and Ahmed; S.; "Techniques of Finite Elements"; Ellis Horwood Limited; 1980

5. Desai, C.S. and Abel, J.p.; "Introduction to the Finite Element Method "; Litton Educational Inc. New York, U.S.A.; 1972

6. Jadhao, Vijay B., and Sanjay B. Ingole. "Vibration analysis of three parameter model of adhesively bonded joints." International Journal of Mechanical and Production Engineering Research and Development 5.1 (2015): 61-72.

7. Patodi; Rajkumar.; "Helical staircase with Landing" M.E. Thesis; University of Roorkee; 1969

8. Gara, Dheeraj K., and Srikar Potnuru. "Quandaries During Numerical Analysis on Shape Memory Product."International Journal of Mechanical and Production Engineering Research and Development (IJMPERD) 10.1, Feb 2020, 271-282

9. Timoshenko; S.P. and Woinowosky, Krieger, S.; "Theory of Plates and Shells"; (2 ${ }^{\text {nd }}$ edition); Me Graw Hills Book co; New York; 1959.

10. Al-Waily, Muhannad, et al. "Influences of Glass and Carbon Powder Reinforcement on the Vibration Response and Characterization of an Isotropic Hyper Composite Materials Plate Structure." International Journal of Mechanical \& Mechatronics Engineering IJMME-IJENS 17.06 (2017). 
